\title{
Hisashi Mizuno, Gérard de Nerval poète en prose
}

\section{Alessandra Marangoni}

\section{(2) OpenEdition}

\section{Journals}

\section{Edizione digitale}

URL: http://journals.openedition.org/studifrancesi/2213

DOI: $10.4000 /$ studifrancesi.2213

ISSN: 2421-5856

\section{Editore}

Rosenberg \& Sellier

\section{Edizione cartacea}

Data di pubblicazione: 1 aprile 2014

Paginazione: 167-168

ISSN: 0039-2944

\section{Notizia bibliografica digitale}

Alessandra Marangoni, « Hisashi Mizuno, Gérard de Nerval poète en prose », Studi Francesi [Online], 172 (LVIII | I) | 2014, online dal 01 avril 2014, consultato il 17 septembre 2020. URL : http://

journals.openedition.org/studifrancesi/2213; DOI : https://doi.org/10.4000/studifrancesi.2213

\section{Questo documento è stato generato automaticamente il 17 settembre 2020.}

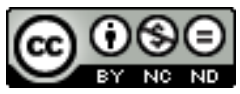

Studi Francesi è distribuita con Licenza Creative Commons Attribuzione - Non commerciale - Non opere derivate 4.0 Internazionale. 


\title{
Hisashi Mizuno, Gérard de Nerval poète en prose
}

\author{
Alessandra Marangoni
}

\section{NOTIZIA}

HISASHI MIZUNO, Gérard de Nerval poète en prose, Paris, Kimé, 2013, pp. 258.

1 Giacché Nerval non è autore di poème en prose, lo studio si pone il chiaro intento di rinvenire la poesia interna alla prosa nervaliana. È interessante l'inusuale punto di partenza: Nerval così come visto dai moltissimi necrologi che seguirono la sua tragica morte, non ultimi quelli di Alexandre Dumas, Arsène Houssaye e Théophile Gautier. L'assunto è il seguente: «la nature du scandale entourant le suicide du poète semble avoir orienté la lecture de son œuvre».

2 È poi affrontato l'importante argomento del germanesimo di Nerval. La traduzione del Faust di Goethe è sì fatta di versi e di prosa, ma col susseguirsi delle edizioni (1827, 1835, 1840) l'autore opta sempre più spesso per la prosa: una prosa vieppiù poetica. Inizialmente debitore nei confronti dello sguardo di Mme de Staël, Nerval fa della lezione proveniente d'oltre Reno un fertile humus per la sua opera, abbinandola senza traumi alla tradizione greco-latina. Ecco nato un sonetto come «Délfica».

3 La poetica del vero prende corpo ne Le Roman tragique contro il risveglio della tragedia classica, alla Ponsard, e nella narrazione delle Nuits d'octobre che descrive i meandri di Parigi con i suoi bassifondi. Con la precisazione che «le narrateur s'écarte en quelque sorte de l'école du vrai lorsqu'il sort de l'enfer parisien»; insomma, quando entra in campo il Valois, il sogno inizia a dettar legge.

4 Pubblicata su «L'Illustration» come Les Nuits d'octobre, la serie Promenades et souvenirs accede a un narrato lirico, discontinuo, musicale. «À l'origine de la prose, il y a la poésie, étroitement liée à la chanson dans l'esprit de Nerval».

5 Il rapporto tra musica e poesia è infatti l'argomento della parte centrale di questo studio che prende in considerazione il pervicace attaccamento di Nerval alla canzone 
popolare e la funzione di quest'ultima all'interno della sua opera. Lo studioso imbastisce inoltre un'interessante dimostrazione sulla presenza di Rousseau nella fattura di Sylvie: si tratta del Rousseau della Nouvelle Héloïse così come divulgato in quegli anni dalla «Revue des Deux Mondes», rivista su cui appunto esce Sylvie. L'io autobiografico nervaliano non si discosterebbe molto da un soggetto lirico: poesia della prosa, in ultima istanza.

6 La parte finale affronta il nodo periglioso della follia, avanzando la seguente ipotesi: «Gérard de Nerval crée une écriture dialogique, à partir de textes de ses amis, pour dire sa folie». I testi con cui si instaura il dialogo sono quelli di Hyppolyte Babou, Jules Janin, Alexandre Dumas. È naturalmente Aurélia l'apice della follia poetica, una follia così lucida e produttiva da suscitare l'ammirazione di Baudelaire.

7 Complementare al singolare punto di partenza, funge da conclusione un panorama sulla ricezione dell'opera di Nerval dal 1855, anno della morte, al 1914, anno della prima biografia scientificamente fondata. 